\title{
Average rate of phenological changes in Poland according to climatic changes - evaluation and mapping
}

\author{
K. Jatczak ${ }^{1,2}$ and J. Walawender ${ }^{3,4}$ \\ ${ }^{1}$ Meteorology Centre, Institute of Meteorology and Water Management, Warsaw, Poland \\ ${ }^{2}$ Faculty of Biology, University of Warsaw, Poland \\ ${ }^{3}$ Satellite Remote Sensing Centre, Institute of Meteorology and Water Management, Poland \\ ${ }^{4}$ Department of Climatology, Institute of Geography and Spatial Management, \\ Jagiellonian University, Krakow, Poland
}

Received: 31 December 2008 - Revised: 7 September 2009 - Accepted: 10 September 2009 - Published: 13 October 2009

\begin{abstract}
The main objective of this study was evaluation and mapping of an average rate of phenological changes for example special plant s indicators as a result of climatic changes in Poland.

Multi-year analysis clearly showed a tendency to earlier onset of spring events. The average advance of flowering/leafing was -1.4 days/decade and -2.4 days $/ 1^{\circ} \mathrm{C}$. Whereas the response of autumn phenophases was ambiguous. Phenological and climate data come from archives of the Institute of Meteorology and Water Management.

Analysis covered the period of 1951-1992. The relation between temperature and date of phenophases was described with Pearson's linear regression model. Statistical significance of the model parameters was checked with Student's t-test at the following levels: 0.05, 0.01, and 0.001.

The results were visualised on maps. ArcGIS 9.2 Geostatistical Analyst was used to examine the data and create prediction maps. Numerous tests were performed in order to find an appropriate method of spatial interpolation. Finally kriging was chosen as the most precise.
\end{abstract}

\section{Introduction}

Changes of climate factors like solar radiation, temperature or precipitation are reflected in various physical and biological ecosystems. Plant species which define Polish environment are typical for European lowlands. The most unique is North-eastern part of Poland with biodiversity of wetlands and lowland European primeval forest (Zimny, 1999).

The main objective of this study was evaluation and mapping of an average rate of phenological changes which exemplify reaction of special plant indicator species to climatic changes in Poland. Correct recognition of the scale of the changes is important for environmental protection and prediction of its further transformations.

Geographic Information Systems (GIS) provide a powerful set of tools for spatial analysis which can be used in many environmental application. In this study GIS was applied to

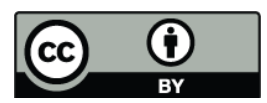

Correspondence to: K. Jatczak

(katarzyna.jatczak@imgw.pl) find the optimal interpolation method in order to create reliable phenological maps.

Source of data: Phenological and climate data used in this study were obtained from archives of the Institute of Meteorology and Water Management. Analyses covered a period from 1951 to 1992. Phenological observation network consisted then of 69 stations (Fig. 1). Statistical calculations were performed for selected 25 phenological stations along with the same number of corresponding meteorological stations, which were located nearby.

\section{Materials and methods}

\subsection{Descriptive statistical analysis}

Analysis were based on phenological phases proposed by Ihne - 14-th of them - typical for Polish environmental conditions (Tomaszewska and Rutkowski, 1999; Meier, 1997). The relation between mean monthly air temperature, date of phenophases and their changes in time was described with Pearson's linear regression model. Calculations were made

Published by Copernicus Publications. 


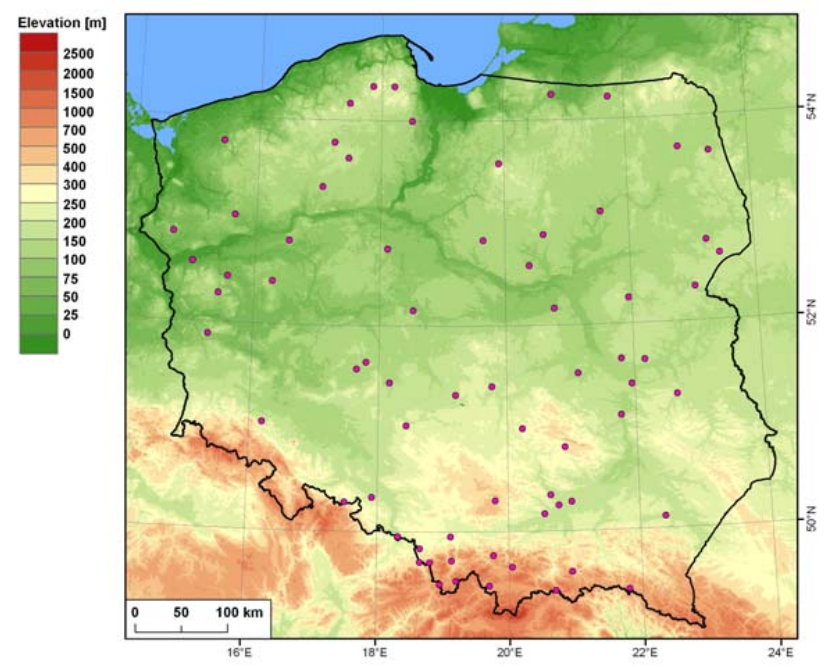

Figure 1. Phenological station network in Poland (1951-1992).

to check to what extend changes in phenological appearance depend on changes of temperature. Statistical significance of the model parameters was checked with Student's t-test at the following levels: $0.05,0.01$ and 0.001 .

Phenological phases characterized by significantly decreasing trend, strongly correlated with reverse trend of mean monthly temperature were regarded as good plant indicators. Analysis of slope $b$ coefficient (days/decade) were made to estimate the scale of changes in phenological appearance (advance/delay) in the period of research: 1951-1992.

The changes from $\leq-1.6$ days/decade (half from the range of average changes) were regarded as important. Analysis of correlation coefficient between phenological data and mean monthly temperature were made in order to check to what extend changes in phenological appearance depend on changes in temperature. It was assumed that correlation coefficients form -1 to -0.5 proved strong dependence on temperature. Analysis of slope $\mathrm{b}$ coefficient (days $/ 1^{\circ} \mathrm{C}$ ) was made to estimate the scale of changes in phenological appearance induced by growth of mean monthly temperature by $1 \mathrm{oC}$. In this case the changes from $\leq-1.8$ days $/ 1^{\circ} \mathrm{C}$ ( half from the range of average changes) were regarded as important.

\subsection{Geostatistical analysis and mapping}

One of the approaches to estimate climate conditions at unsampled locations is spatial interpolation. There are several approaches available to create continuous surfaces from spatial sample data. Unlike deterministic methods (e.g. Inverse Distance Weighting (IDW) or Splines), geostatistical methods use a stochastic approach and a model of the spatial variation of properties (Schröder et al., 2006). Geostatistics assumes that measurements lying closer together are more related to each other than those farther apart.
All spatial interpolation methods require relatively dense network of base stations representing various topographical and geographical conditions (Hunter and Meentemeyer, 2005). This condition was partially met in the study as the phenological stations are more or less evenly spread out across Poland. On the other hand only four of them were typically mountainous stations (located $500 \mathrm{~m}$ a.s.l. or higher).

Geostatistical analysis of the phenological data and mapping procedures were carried out within GIS environment. The GIS (Geographic Information Systems) have recently become a very significant and rapidly developing tool, which has a growing importance in many environmental applications, including meteorology and climatology (Dobesch et al., 2001). In this study ArcGIS 9.2/9.3 with Geostatistical Analyst were used: to examine the data, to select adequate interpolator, to create prediction maps and to assess the accuracy of interpolation.

The geostatistical analysis of the data was performed taking into account specific nature of phenological data which is obtained during subjective observations and is highly dependent on local environmental conditions.

It was decided to exclude from the analysis the four stations elevated higher than $500 \mathrm{~m}$ a.s.l. because only four of them were not enough to model spatial distribution of phenological data in mountainous regions even when applying "elevation" (height above sea level) as additional (explanatory) variable. Furthermore only the data which fell within the range of two standard deviations (+/-) from the mean value were taken into account during interpolation. The outstanding data were taken as "uncertain extremes", which are probably erroneous.

In this study ordinary kriging interpolation method with spherical semivariogram model was chosen as it is the simplest stochastic interpolator and remarkably flexible method, which gives relatively good results. All kriging interpolators minimise the estimation variance and rely on weighted averaging of the measured values within the autocorrelation range (Olea, 1999).

Accuracy of the kriging estimations was assessed by calculating standard prediction errors (ArcGIS 9, Using ArcGIS Geostatistical Analyst). Obtained values of Root Mean Square Error (RMSE) and Root Mean Square Standardized Error(RMSSE) are presented in Table 1. Assessments of RMSSE very close to 1 proved satisfactory interpolation results. 
Table 1. Prediction errors.

\begin{tabular}{cccccccccc}
\hline \multirow{2}{*}{ Prediction error } & \multicolumn{3}{c}{ Mean phenophase date } & \multicolumn{3}{c}{ Mean phenophase change [Days/Decade] } & \multicolumn{3}{c}{ Mean phenophase change [Days $\left./ 1^{\circ} \mathrm{C}\right]$} \\
\cline { 2 - 11 } & $\begin{array}{c}\text { leaves } \\
\text { unfolding }\end{array}$ & $\begin{array}{c}\text { leaves } \\
\text { colouring }\end{array}$ & $\begin{array}{c}\text { falling of } \\
\text { leaves }\end{array}$ & $\begin{array}{c}\text { leaves } \\
\text { unfolding }\end{array}$ & $\begin{array}{c}\text { leaves } \\
\text { colouring }\end{array}$ & $\begin{array}{c}\text { falling of } \\
\text { leaves }\end{array}$ & $\begin{array}{c}\text { leaves } \\
\text { unfolding }\end{array}$ & $\begin{array}{c}\text { leaves } \\
\text { colouring }\end{array}$ & $\begin{array}{c}\text { falling of } \\
\text { leaves }\end{array}$ \\
\hline RMSE & 0.8445 & 1.843 & 3.988 & 1.439 & 3.144 & 7.829 & 1.25 & 2.572 & 5.792 \\
RMSSE & 1.03 & 1.02 & 0.9846 & 1.004 & 0.9664 & 1.017 & 1.074 & 0.9897 & 1.054 \\
\hline
\end{tabular}

Table 2. Comparison of main trend coefficients.

\begin{tabular}{|c|c|c|c|c|}
\hline \multirow[t]{2}{*}{ Scientific Name } & \multirow[t]{2}{*}{ Event } & \multicolumn{3}{|c|}{ mean value for 25 stations } \\
\hline & & $\begin{array}{c}\text { slope b } \\
\text { (days/decade) }\end{array}$ & $\begin{array}{c}\text { correlation } \\
\text { coefficient }(r)\end{array}$ & $\begin{array}{c}\text { slope b } \\
\left(\text { days } / 1^{\circ} \mathrm{C}\right)\end{array}$ \\
\hline \multicolumn{5}{|l|}{ Spring phases } \\
\hline Corylus avellana & begining of flowering & -2.4 & -0.7 & -2.6 \\
\hline Tussilago farfara & begining of flowering & -0.7 & -0.5 & -2.5 \\
\hline Padus avium & begining of flowering & -0.5 & $-0.3 ;-0.4 ;-0.5$ & -1.4 \\
\hline Taraxacum officinale & begining of flowering & -2.4 & -0.4 & -2.4 \\
\hline Betula pendula & leaves unfolding & -1.9 & -0.5 & -3.0 \\
\hline Siringa vulgaris & begining of flowering & -0.5 & -0.4 & -1.1 \\
\hline Aesculus hippocastanum & begining of flowering & -0.7 & -0.6 & -2.4 \\
\hline \multicolumn{5}{|l|}{ Summer phases } \\
\hline Robinia pseudoacacia & begining of flowering & -2.7 & -0.5 & -2.7 \\
\hline Tilia cordata & begining of flowering & -0.3 & -0.3 & -1.7 \\
\hline \multicolumn{5}{|l|}{ Autumn phases } \\
\hline Aesculus hippocastanum & first ripe fruits & -0.3 & $-0.2 ;-0.1$ & -0.4 \\
\hline Calluna vulgaris & begining of flowering & 0.5 & -0.1 & -0.9 \\
\hline Aesculus hippocastanum & colouring of leaves & -1.2 & -0.1 & -0.2 \\
\hline Betula pendula & coluring of leaves & -2.3 & -0.2 & -0.2 \\
\hline Betula pendula & falling of leaves & -1.0 & -0.1 & 0.6 \\
\hline
\end{tabular}

\section{Results}

Multi-year analysis clearly showed tendency to earlier onset of spring events (Table 2., Figs. 2, 3). The biggest average advance of phenological events was observed in case of three phases:

- flowering of Corylus avellana - advance by -2.4 days/decade and -2.6 days $/ 1^{\circ} \mathrm{C}$ with correlation coefficient with temperature -0.7 ,

- leaves unfolding of Betula pendula Roth. - advance by -1.9 days/decade and -3 days $/ 1^{\circ} \mathrm{C}$ ) with correlation coefficient with temperature -0.5

- flowering of Robinia pseudoacacia - advance by -2.7 days/decade and -2.7 days $/ 1^{\circ} \mathrm{C}$ with correlation coefficient with temperature -0.5 .

The response of autumn phenophases was ambiguous. Slight mean advance of birch leaves coloring by -0.2 days $/ 1^{\circ} \mathrm{C}$, not significantly correlated with air temperature

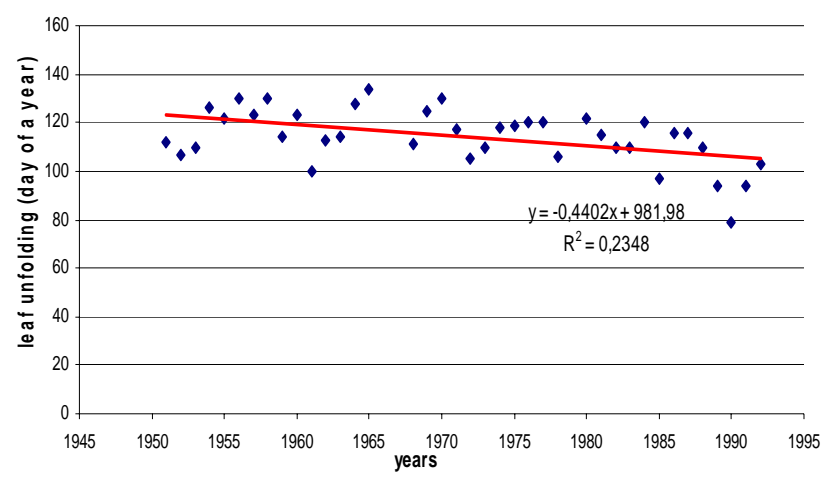

Figure 2. Trend of leaf unfolding date of silver birch date at a selected station $(1951-1992)(p<0.01)$.

was observed as opposed to leaves falling which was delayed 0.6 days $/ 1^{\circ} \mathrm{C}$ (Table 2 ).

Achieved results are very similar to the research done in different European countries (Menzel et al., 2006). 


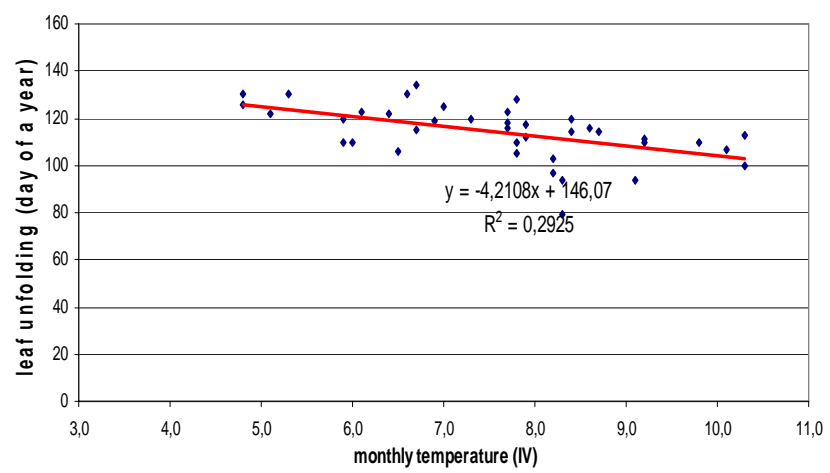

Figure 3. Correlation of monthly air temperature (IV) in ${ }^{\circ} \mathrm{C}$ and leaf unfolding date of silver birch at a selected station (1951-1992) $(p<0.01)$

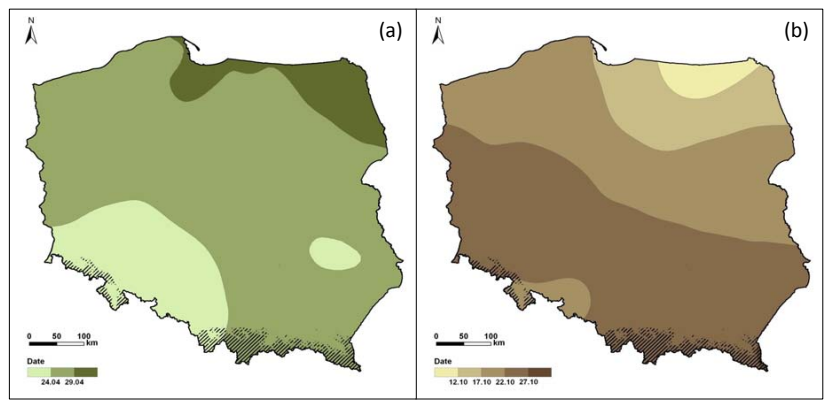

Figure 4. Average appearance time of birch leaf unfolding (a) and falling ((b).

Differences between the phase onset dates in Germany and Slovakia can be found especially for early spring. The onset dates are sooner and the year-to-year variability is higher in Germany comparing to Slovakia (Bissolli et al., 2005).

We were looking for the best visualization method of the scale of phenological changes in Poland. Created maps reflect advance of spring events - high dynamic of average rate of changes all over the Poland (similar tendency in most regions) (Figs. 5a, 6a - leaves' unfolding advance is from -2 to -1 days/decade and from -3.5 to -2.5 days $/ 1^{\circ} \mathrm{C}$ in major area).

Diversified response of autumn phenophases was also identified in the maps. (one region - advance, another - delay) (Fig. 6b. Dynamic of average rate of changes was low leaves' falling changes from 0 to 1 days $/ 1^{\circ} \mathrm{C}$ in almost entire country, mainly in central Poland with phenophase delayed in the north-east and slight advance in the north-west and the South-east).

Created maps present spatial distribution of phenological parameters for the whole country not taking into account any influence of mountainous areas $(\mathrm{h} \geq 500 \mathrm{~m}$ a.s.l) which were hatch-patterned in the maps.

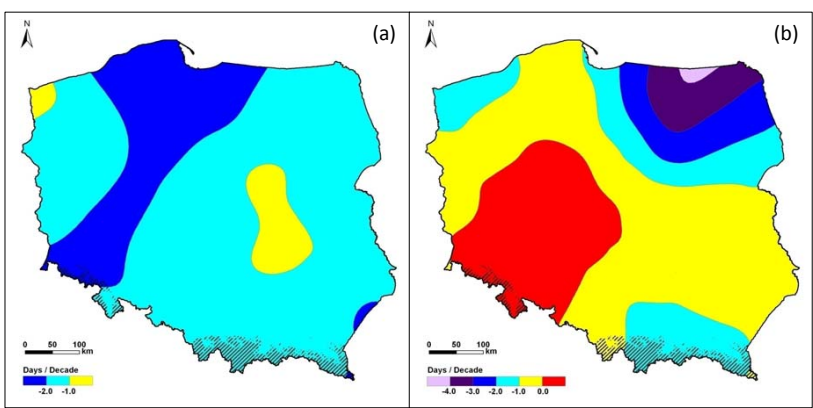

Figure 5. Average rate of changes (days/decade) of birch leaves unfolding (a) and falling (b).

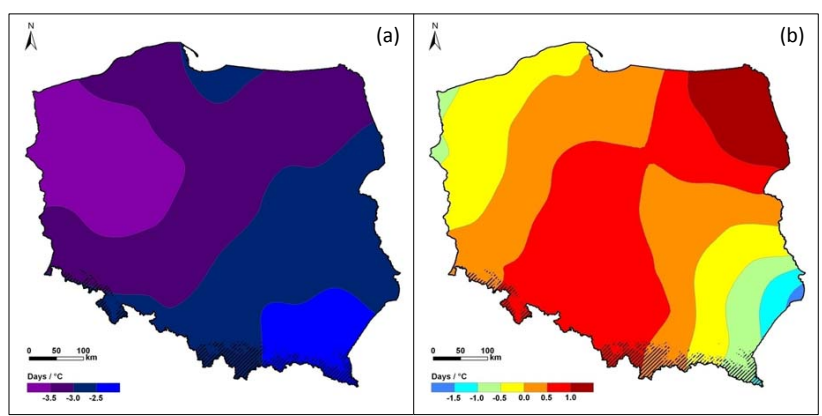

Figure 6. Average rate of changes $\left(\right.$ days $\left./ 1^{\circ} \mathrm{C}\right)$ of birch leaves unfolding (a) and falling (b).

\section{Conclusions}

Geographical Information Systems (GIS) and geostatistics used in this study are valuable tools for an objective analysis of the phenological data to determine optimal interpolation method. GIS made it possible to analyse spatial distribution of average rate of phenological changes in Poland and to create reliable phenological maps. Phases with significant changes and those without any direct tendency are very clearly seen on the maps. The advance of phenological phases, especially in spring season was significantly correlated with air temperature of the preceding month. Creation of maps is necessary to perform successful spatial analysis of phenological data and helps in better understanding of average rate of phenophase changes. Kriging seems to be the appropriate interpolation method to explain spatial distribution of phenological phase's appearance time and the average tendency for each phenophase. Much denser phenological station network in the mountains would be needed in order to examine influence of mountains on spatial distribution of phenological data.

Edited by: E. Koch

Reviewed by: two anonymous referees 


\section{References}

ArcGIS 9,Using ArcGIS Geostatistical Analyst (user manual): http://dusk2.geo.orst.edu/gis/geostat_analyst.pdf, last access: 23 September 2008.

Bissolli, P., Dittmann, E., Remisova, V., et al.: 50-year time series of phenological phases in Germany and Slovakia: a statistical comparison, Meteorol. Z., 14, 2, 173-182, 2005.

Dobesch, H., Tveito, O. E., and Bessemoulin, P.: Final Report Project no. 5, in the framework of the climatological projects in the application area of ECSN, 'Geographic Information Systems in Climatological Application', Oslo-Vienna, 2001.

Hunter, D. R. and Meentenmeyer, R. K.: Climatologically aided mapping of daily precipitation and temperature, J. Appl. Meteorol., 44, 1501-1510, 2005.

Meier U.: Growth Stages of Plants, Blackwell WissenschaftsVerlag, Berlin, Wien, 1997.
Menzel, A., Sparks, T., Estrella, N., et al.: European phenological response to climate change matches the warming pattern, Global Change Biol., 12, 1969-1976, 2006.

Olea, R. A.: Geostatistics for Engineers and Earth Scientists, Kluwer Academic Publishers, Boston, Dordrecht, London, 1999.

Schröder, W., Schmidt, G., and Hasenclever, J.: Geostatistical analysis of data on air temperature and plant phenology from Badden-Württenberg (Germany) as a basis for regional scaled models of climate change, Environmental Monitoring and Assesment, 120, 27-43, 2006.

Tomaszewska, T. and Rutkowski, Z.: Fenologiczne pory roku i ich zmienność w wieloleciu 1951-1990", Materialy Badawcze IMGW 28, 1999.

Zimny, H.: Wybrane zagadnienia z ekologii, SGGW, Warszawa, 1997. 